\title{
The Use of Hybrid Terms and Expressions in Colloquial Arabic among Jordanian College Students: A Sociolinguistic Study
}

\author{
Samia A. Jaran ${ }^{1} \&$ Fawwaz Al-Abed Al-Haq ${ }^{1,2}$ \\ ${ }^{1}$ Department of English Language and Literature, Faculty of Arts, Yarmouk University, Irbid, Jordan \\ 2 The Vice President for Academic Affairs, Tafila Technical University, Tafilah, Jordan \\ Correspondence: Fawwaz Al-Abed Al-Haq, the Vice President for Academic Affairs, Tafila Technical University, \\ Tafilah, Jordan. E-mail: fawazm57@gmail.com
}

\author{
Received: September 5, 2015 Accepted: November 14, 2015 Online Published: November 16, 2015 \\ doi:10.5539/elt.v8n12p86 URL: http://dx.doi.org/10.5539/elt.v8n12p86
}

\begin{abstract}
Languages tend to be modified to accommodate for the speakers needs, such as, discussing or dealing with certain topics and domains. An example, university students, in Jordan, modify their own language, being colloquial Arabic, with terms and expressions from the English language in order to interact and adapt to everyday college life. Due to this, college students have fabricated new hybrid terms and expressions; a mixture of English and colloquial Arabic words merged together to make one. This study attempts to explain the attitudes towards these terms and expressions and to what extent they are used amongst the students at Yarmouk University, during Arabic discourse. This was achieved by means of questionnaires and interview. The findings revealed that these colloquial hybrid terms and expressions are highly used by all college students. Results also show that the use of colloquial hybrid terms and expressions is tightly related to social factors, like, age and gender. Thus, these terms and expressions are used mostly by students aged between 18 and 20 years of age. Moreover, these terms and expressions are used more by females than males.
\end{abstract}

Keywords: accommodation theory, hybrid terms and expressions, social factors, students, university domain

\section{Introduction}

A speaker's attitudes towards other speakers in a conversation can influence the way they speak. A social psychological approach to language variation, Accommodation Theory - more precisely Speech Accommodation Theory (SAT) - first appeared in 1970s and can be traced back to the British language psychologist Howard Giles (1973). The theory aims at providing an explanation for why speakers accommodate - i.e., change the manner in which they speak - in face-to-face interaction.

According to Giles' (1973) accommodation theory, speakers may alter their speech in the purpose of sounding more like others they speak with to achieve greater social integration with them. Nevertheless, Giles' approach handles not only convergence through accommodation, but also divergence, where speakers can employ deliberate linguistic differences as a symbolic act for maintaining and asserting their distinct identity (Giles, 1973; H. Giles, J. Coupland \& N. Coupland, 1991)

Every language is, to some extent, mixed but only a few languages are considered "mixed languages" as in the particular sense meant here. A mixed language differs from code-switching, in which, once it has been developed, the fusion of the two languages is fixed in grammar and vocabulary. Arends, Muysken, and Smith (1994) categorise an "intertwined language" as a language that "has lexical morphemes from one language and grammatical morphemes from another".

"Arabizi", a mixing of Arabic and English, a new linguistic phenomenon used by Arab youths in everyday written and spoken communication as a means of accommodating with the influence of modernisation and globalisation on their daily life.

Upon hearing the term "Arabizi”, many questions may come to one's mind; What exactly is Arabizi? Where did it come from? Who speaks it? In general, the term Arabizi is, as pointed out by Yaghan (2008), a coined form of the two words "Yarabi" (Arabic) and "englizi" (English) (Yaghan, 2008: 39).

The term "Arabizi" can be considered as a sociolinguistic device to accommodate oneself to the norms of a 
"speech community", as it is a trend that everyone is coping with these days (Bassiouney, 2009).

An Arabizi is a significant phenomenon related to the written and spoken Arabic as used by mostly all Arab youths as a means of communication, not only on the sentence level, by internalising English terms and expressions into Arabic discourse, but also on the word level, by tensing English words in Arabic. For instance, "chabāter" meaning chapters and "lābāt" meaning labs. As can be seen by the preceding examples, an English words is pluralised by applying the Arabic plural form to it, therefore, creating and an Arabised plural form of an English word.

An additional variation of Arabizi is the classical addition of English suffixes to the end of Arabic words, as in, "zift-ation" pronounced /zifteIfon/ (zift as from the English word asphalt) connotatively meaning "not good" and "zoog-less" pronounced /zouglis/ or /zoullis/ connotatively meaning "has no manners". These terms and expressions have come to represent an amalgamation of two languages, and as a result that of two cultures, traditionally viewed as separate.

These kinds of terms and expressions are often described by authors with terms, such as, 'intertwined', 'hybrid', 'fusion', 'collage', and 'eclectic'. Hence, "Hybrid Words", defined by Crystal (2008) as, "a word composed of elements from different languages". An example of a hybrid term is "mono-lingual", which has a Greek prefix and a Latin root (Crystal, 2008: 232).

The idea of using alternate language models in a spoken language is a familiar one. However, hybrid terms and expressions are difficult since their usage is not predicted from the speaker. The problems which arise are deciding which language model(s) to use and when to change language models. In Arab countries, the English language is considered as a foreign language, but for some it has become part of their everyday life. In universities, many courses are given in English, in consequence, when university students communicate with one another in Arabic about university topics, they tend to include English words and/or phrases.

In response to these problems, our study comes as an attempt to cover this area of research, and shed light on the reasons behind why and when hybrid terms and expressions are used among university students in Jordan, from a sociolinguistic perspective. Furthermore, the acceptance of these terms and expressions and the different attitudes towards them.

The present study aims to investigate the justifications behind the use of Arabic-English hybrid terms and expressions amongst students in Jordanian universities. In addition, it attempts to account for when and why they are used. The study also examines the students' attitudes towards the use of hybrid terms and expressions.

In an attempt to achieve the study's purpose, the researcher seeks answers for the following three primary question:

1). What are students' attitude towards the use of colloquial Arabic-English hybrid terms and expressions?

2). When and why are colloquial Arabic-English hybrid terms and expressions used?

3). To what extent are colloquial Arabic-English hybrid terms and expressions used?

The researcher assumes that the setting and topic of context have an impact on the use of hybrid terms and expressions. She also assumes that variation in use of these terms and expressions are influenced by the age, gender, major, educational level, and the language in which the students are taught.

Arabic-English hybrid terms and expressions are used by many university students as a means of communication. This study highlights hybrid terms and expressions and the extent of their use among students in some Jordanian universities, indicating to what extent are Jordanian students aware of the use of hybrid terms and expressions within their society. This study looks into general reasons behind the use of hybrid terms and expressions in university student communication, an area that has not received much attention so far. Therefore, it classifies the reasons of when and why hybrid terms and expressions are used. Furthermore, it highlights the different attitudes towards the use of hybrid terms and expressions, negative or positive, within Arabic discourse.

\section{Methods and Procedures}

The participants constituted a total of 150 randomly chosen Jordanian students enrolled in different faculties affiliated with Yarmouk University, in the northern area of Jordan - Irbid, for the academic year 2014/2015. The distribution of the sample, according to student's major, is as the following: 16 students (10.7\%) enrolled in the Department of Arabic, 9 students (6.0\%) in the Department of English, 9 students (6.0\%) in the Faculty of Arts, 9 students (6.0\%) in the Faculty of Science, 22 students (14.7\%) in the Faculty of Economics and Administrative Sciences, 11 students (7.3\%) in the Hijjawi Faculty for Engineering Technology, 8 students $(5.3 \%)$ in the Faculty of Shari'a and Islamic Studies, 19 students (12.7\%) in the Faculty of Education, 6 students (4.0\%) in the Faculty 
of Physical Education, 2 students (1.3\%) in the Faculty of Fine Arts, 9 students $(6.0 \%)$ in the Faculty of Information Technology and Computer Science, 5 students (3.3\%) in the Faculty of Archaeology and Anthropology, 4 students (2.7\%) in the Faculty of Mass Communication, 6 students $(4.0 \%)$ in the Faculty of Tourism and Hotel Management, 10 students (6.7\%) in the Faculty of Medicine and Pharmacy, and 5 students (3.3\%) not stated. Accordingly, 80 students (53.3\%) study in the Arabic language and 68 students $(45.3 \%)$ study in the English language, and 2 students (1.3\%) did not provide an answer.

The average respondent is a Jordanian university student in the first, second, or third year of study. 79 males made up $52.7 \%$ of the sample, whereas 71 females made up $47.3 \%$ of the sample. The majority respondents were in the age range of $18-20$ years of age.

Both qualitative and quantitative research approaches were combined in an effort to obtain accurate outcomes and sufficient information from the respondents. The needed data were collected by two methods: firstly, by means of interview and observation of naturally occurring data. The frequently used terms and expressions by students during natural chat, which took place in a comfortable environment in various departments within the Yarmouk University, were documented. The setting and topic of the conversation in which these terms and expressions occurred were also documented. Some students were asked a number of oral questions in order to measure the extent and justifications behind the use of the English language in the daily speech of students within the university domain.

Secondly, in order to measure students' attitudes towards colloquial hybrid terms and expressions used in spoken communication among students in Jordanian universities, a questionnaire based on that used by Hussein (1999) was administered to the students.

The student questionnaire consists of two main sections and 30 items. The first 5-item section, "Personal Information", elicited data on gender, age, major, educational level, and the language in which the students are taught. The second section ( 24 item likert-scale) elicited data on students' attitudes towards colloquial English-Arabic hybrid terms and expression. The last item elicited data on students' use of these terms and expressions, and the most frequently used terms and expressions within discourse.

The questionnaire was written in both English and Arabic to ease the participant's understanding of the items and to achieve more accurate results. The questionnaire was administered to the students after a brief introductory talk, in which, the completion procedure was explained. Completion of the questionnaire was administered under the supervision of a respective lecturer.

The data collected from the questionnaire was tabulated onto computer sheets and then analysed statistically, using a data base programme, in order to highlight the colloquial hybrid terms and expressions phenomenon as used by students in some Jordanian universities. Two types of statistics were used, frequencies and percentages. The statistics were analysed and described the usage of colloquial hybrid terms and expressions as a means of communication among students in some Jordanian universities.

To establish when and why, and to what extent colloquial Arabic-English hybrid terms and expressions are used amongst the students, 50 students were interviewed; asking them 14 questions in total. Unfortunately, they did not accept to be recorded. Before asking the questions, the students were asked to provide some basic information, mainly their age, major, and level of educational. The information, along with the answers of the questions, were also tabulated and analysed statistically.

\section{Results and Discussion}

All the responses were gathered, counted and categorised according to the points in question. The identified colloquial hybrid terms and expressions were compared according to the speaker's gender groups, age groups, major, educational level, and the language in which the students are taught.

According to the language in which the students are taught, students were asked to provide whether their major is taught in the Arabic language or in the English language. The results indicated that most of the students are taught in the Arabic language, a total of 80 (53.4\%) students (37 males and 43 females). This is due to the random sampling, where most of the students are from faculties in which major subjects are given in Arabic, such as, the Faculty of Shari'a and Islamic Studies and the Faculty of Education.

For students that are taught in the English language, they were asked "In which language would you prefer the courses to be taught?". There was a strong and evident agreement in the opinion expressed by students. The majority of students (56 out of 68 students) preferred Arabic/English code-switching to the total use of the English language, which was preferred by only 12 students ( 2 students did not provide an answer). This demonstrates a strong preference for the Arabic/English code-switching as a medium of instruction. The 
following statements are some of the student's responses: "it is better [to] use English because it make[s] us understand future references about the subject, however, difficult words should be explained in Arabic then translated to English". Another comment was "In my first two year[s] I want English and Arabic but after I want English only". Another reason suggested by a student is "Arabic in [the] first year help [s] me [to] understand because I studied high school in Arabic". However, for the students who preferred the English language to be the medium of teaching, they explained their preference by stating, "because we work in hospitals the language we use is English so it is more important than Arabic".

However, the language in which students are taught does not really show if students are aware of or use hybrid terms and expression when communicating with one another. As although they are taught in the Arabic language, students are required to take obligatory subject/courses, such as English 101, which are given in English, and from these courses or subjects students may pick up or even create new hybrid terms and expressions as they interact with other students from different departments enrolled in majors which are taught in the English language.

\subsection{University Students' Attitudes towards Colloquial Hybrid Terms and Expressions}

Under this heading, we will discuss students' responses of the second section of the questionnaire, comprising 24 items and intended to elicit students' attitudes towards Colloquial Hybrid Terms and Expressions. We will discuss these attitudes under four subheadings: attitudes towards Colloquial Hybrid Terms and Expressions in relation to Arabic (items 1, 3, 6, 11, 15, 21, 22, 23, and 24), attitudes towards Colloquial Hybrid Terms and Expressions in relation to English and western culture (items 2, 4, 12, and 14), attitudes towards Colloquial Hybrid Terms and Expressions in relation to general communication (items 5, 16, 17, 18, 19 and 20), and finally, attitudes towards Colloquial Hybrid Terms and Expressions in relation to users (items 7, 8, 9, 10, and 13).

Table 1. Students' attitudes towards hybrid expressions

\begin{tabular}{|c|c|c|c|c|}
\hline & Item & Agree\% & Uncertain \% & Disagree\% \\
\hline 1 & Those who use Arabizi are deficient in the Arabic language. & 19.3 & 18.0 & 62.7 \\
\hline 2 & Those who use Arabizi better express technological concepts. & 48.0 & 24.7 & 27.3 \\
\hline 3 & Those who use Arabizi 'pollute' the Arabic language. & 61.3 & 15.3 & 23.3 \\
\hline 4 & Those who use Arabizi are loyal to the English language. & 31.3 & 36.7 & 32.0 \\
\hline 5 & Those who use Arabizi enhance communication with others. & 49.3 & 26.0 & 24.7 \\
\hline 6 & $\begin{array}{l}\text { Those who use Arabizi enrich the Arabic language and its } \\
\text { lexicon. }\end{array}$ & 42.0 & 28.0 & 30.0 \\
\hline 7 & Those who use Arabizi do so to show they are educated. & 68.0 & 20.0 & 12.0 \\
\hline 8 & Those who use Arabizi do so to show they are modernised. & 71.3 & 18.7 & 10.0 \\
\hline 9 & Those who use Arabizi are respected by others. & 24.7 & 40.0 & 35.3 \\
\hline 10 & Those who use Arabizi pride themselves on speaking English. & 60.7 & 23.3 & 16.0 \\
\hline 11 & $\begin{array}{l}\text { Those who use Arabizi dissociate themselves from the Arabic } \\
\text { culture. }\end{array}$ & 47.3 & 37.3 & 15.3 \\
\hline 12 & $\begin{array}{l}\text { Those who use Arabizi favour integration with the western } \\
\text { culture. }\end{array}$ & 64.0 & 26.0 & 10.0 \\
\hline 13 & Those who use Arabizi belong to a higher socio-economic class. & 30.0 & 26.0 & 44.0 \\
\hline 14 & $\begin{array}{l}\text { People use Arabizi because the English language is rich with } \\
\text { technical terms. }\end{array}$ & 57.3 & 18.7 & 24.0 \\
\hline 15 & People use Arabizi because of a lack of Arabic equivalents. & 43.3 & 16.0 & 40.7 \\
\hline 16 & People use Arabizi to let others understand what they say. & 40.7 & 21.3 & 38.0 \\
\hline 17 & Those who use Arabizi do so in discussing certain topics. & 54.0 & 24.7 & 21.3 \\
\hline 18 & Arabizi is used by everyone. & 28.7 & 30.0 & 41.3 \\
\hline 19 & The use of Arabizi is accepted by everyone. & 35.3 & 28.7 & 36.3 \\
\hline 20 & $\begin{array}{l}\text { Arabic-English expressions are most common among the younger } \\
\text { generation. }\end{array}$ & 72.0 & 19.3 & 8.7 \\
\hline
\end{tabular}


21 Mixing of Arabic and English leads to the weakness of the Arabic language.

71.3

29.3

27.3

82.0
15.3

14.0

11.3
13.3

56.7

66.0

6.7

\subsubsection{Attitudes towards Colloquial Hybrid Terms and Expressions in Relation to Arabic}

Item 1 clearly shows that $62.7 \%$ of the sample "disagrees/strongly disagrees" with the statement that "those who use Arabizi are deficient in the Arabic language", in comparison, 19.3\% "agree/strongly agree" and $18.0 \%$ are "uncertain". It seems that there is no interrelation between the use of hybrid terms and expressions and the deficiency of Arabic, and that people simple use hybrid terms and expressions to fulfil certain language functions. Item 3 elicited responses to the statement "those who use Arabizi 'pollute' the Arabic language". While $61.3 \%$ "agreed/strongly agreed", only $23.3 \%$ "disagreed/strongly disagreed". These percentages show agreement with some researchers who have quarrelled that the interference of one language on another may "take away the purity of the language" (Sanchez, 1987, as cited by Hussein, 1999). The researchers assert that speakers must keep to one language at a time, without mixing, in order to keep a language pure.

Responses to item 6, which states "those who use Arabizi enrich the Arabic language and its lexicon", shows that $30.0 \%$ "disagree/strongly disagree" while $42.0 \%$ "agree/strongly agree". This is in line with some researches, as it is believed that mixing languages, in this case mixing Arabic with English, inevitably enriches the Arabic language since new ways of expressing concepts and notions become accessible to Arab speakers.

In response to item 11, which elicited students' attitudes towards the statement "those who use Arabizi dissociate themselves from the Arabic culture", 47.0\% "agreed/strongly agreed"; and a meagre $15.0 \%$ "disagreed/strongly disagreed". In regards to item 15, which states "people use Arabizi because of a lack of Arabic equivalents", responses show that students were almost equal divided between the two extremes. Where $43.3 \%$ "agreed/strongly agreed", and $40.7 \%$ "disagreed/strongly disagreed". This came as a surprise, as Arabic is desperately lacking in scientific and technological terminology. It is believed that one of the major motivations behind language mixing is the lack of equivalents particularly in specialised technological and scientific domains. It would take a long time for Arabic to catch up with specialised lexicons.

In response to item 21, which states "mixing of Arabic and English leads to the weakness of the Arabic language", $71.3 \%$ "agreed/strongly agreed" and 13.3\% "disagreed/strongly disagreed". As expected, this is in line with the responses of item 3, were the mixing of Arabic and English may lead to the pollution and then to the weakness of the Arabic language.

In response to item $22,56.7 \%$ of the sample "disagreed/strongly disagreed" that the Arabic language must be enriched by other languages. This is in agreement with the responses to item 6 . Whereas, $66.0 \%$ of the sample "disagreed/strongly disagreed" that mixing Arabic and English will lead to the death of the Arabic language. And $82.0 \%$ of the sample "agreed/strongly agreed" that the Arabic language must be protected, developed, and promoted in order for it to survive. The percentages indicate that Arabic is endangered and may be exposed to extinction at any time, unless something is done to prevent so. While on the other hand, some state that the Arabic language is a strong language and will never be extinct, as it is sacred and glorious, the language of The Glorious Quran.

3.1.2 Attitudes towards Colloquial Hybrid Terms and Expressions in Relation to English and the Western Culture

It is evident that responses to item 2 which states "those who use Arabizi better express technological concepts" tilted towards agreement: $48.0 \%$ of the sample expressed agreement whereas $27.3 \%$ expressed disagreement. This is in line with some researches, as it is believed that mixing Arabic with English helps speakers better express technological concepts related to technology, science, and computer sciences. 
In response to item 4, which states "those who use Arabizi are loyal to the English language", $32.0 \%$ expressed disagreement and 31.3\% expressed agreement. Although students tended to reject the idea, the responses were almost divided. Showing that students are well aware that those who mix Arabic with English are not necessarily loyal to English, but rather, language mixing seems to serve their needs for communicating an idea or thought.

Responses to item 12, which states "those who use Arabizi favour integration with the western culture", show that $64.0 \%$ "agreed/strongly agreed" while only $10.0 \%$ "disagreed/strongly disagreed".

In response to item 14, which states that "people use Arabizi because the English language is rich with technical terms", indicates that the majority 57.3\% "agreed/strongly agreed", whereas $24.0 \%$ "disagreed/strongly disagreed". It is unambiguously true that whereas English is rife with scientific and technological vocabulary, Arabic, on the other hand, is deplorably poor in such vocabulary.

\subsubsection{Attitudes towards Colloquial Hybrid Terms and Expressions in Relation to General Communication}

In response to item 15, which states "those who use Arabizi enhance communication with others", $49.3 \%$ "agreed/strongly agreed" compared to $24.7 \%$ who "disagreed/strongly disagreed". This comes to show that the use of hybrid terms and expressions is one way to enhance communication, making it more effective, especially amongst doctors, engineers, and computer programmers who find it easier to communicate through sharing an English specialised lexicon or by and English-Arabic hybrid lexicon. Responses to item 16, which states "people use Arabizi to let others understand what they say", indicate that the students were almost equally divided between the two extremes. Where $40.7 \%$ showed agreement, $38.0 \%$ showed disagreement and $21.3 \%$ who were "uncertain". It was expected that a higher percentage would consent to the statement. According to Grosjean, mixed languages "sometimes serves intent of excluding someone from a conversation, to convey confidentiality, anger and annoyance, to change the speaker's role, etc." (Grosjean, 1982, as cited by Hussein, 1999: 285).

Responses to item 17, which states "those who use Arabizi do so in discussing certain topics", elicited that $54.0 \%$ "agreed/strongly agreed" whereas $21.3 \%$ "disagreed/strongly disagreed". This ties in well with the fact that many people, especially doctors, pharmacists and engineers, mix languages when they consult one another. This is also true of businessmen and economists in striking deals or transactions.

Responses to item 18 , was expected, as $41.3 \%$ "disagreed/strongly disagreed", elicited that hybrid terms and expressions are not used by everyone. While the divided responses to item 19, as $36.0 \%$ showed agreement and $35.3 \%$ showed disagreement, indicates that the attitude towards the use of hybrid expressions is 50/50. Where one may accept it another may not. According to item 20, the majority of response indicate that hybrid expressions are use mostly by the younger generation, where a total of $72.0 \%$ showed agreement to the statement.

\subsubsection{Attitudes towards Colloquial Hybrid Terms and Expressions in Relation to the User}

In response to item 7, which states "those who use Arabizi do so to show they are educated", $68.0 \%$ show "agreed/strongly agreed" while only $12.0 \%$ show "disagreed/strongly disagreed". This positive interrelationship between the use of hybrid expressions in one hand and education in the other is unquestionably true, for language mixing is accessible to those who have had sufficient schooling to enables them to alternate codes in their verbal behaviour. Item 8 elicited responses to the statement "those who use Arabizi do so to show they are modernised". Whereas $71.3 \%$ showed "agreed/strongly agreed", only $10.0 \%$ showed disagreement. This was expected, as stated by Hussein (1999) that the knowledge of the English language "makes it possible for speakers to have access to publications published not only in English-speaking countries but in other countries as well, since English is unquestionably the number one language of publication nowadays". Through the access to these publications, non-native speakers acquire qualities of modernisation and openness which may not be obtainable by speakers who lack the knowledge of the English language.

Responses to item 9, which states "those who use Arabizi are respected by others", indicate that 35.3\% "disagreed/strongly disagreed" compared to $24.7 \%$ who "agreed/strongly agreed", and $40.0 \%$ who were "uncertain". Respect as a social value arises from a number of factors such as education, social status, personality characteristics and knowledge of English; but as shown by the responses, a majority of students were uncertain indicating that the factors may vary over time or that people have become unsure of what factors determine respect or disrespect of others.

In Response to item10, $60.7 \%$ showed "agreed/strongly agreed" to the statement that "those who use 
Arabizi pride themselves on speaking English", and 16.0\% showed disagreement to the statement. Responses to item 13, which states "those who use Arabizi belong to a higher socio-economic class", show that $44.0 \%$ "agreed/strongly agreed" in comparison to $30.0 \%$ who disagreed with the statement. It is believed that the interrelationship between the socio-economic status and the ability to language mix is too obvious to belabour. Generally, it is thought that if someone language mixes then that someone must be an educated person (a doctor, surgeon, engineer, scientist, computer programmer, teacher, etc.) and thus belongs to a relatively higher socio-economic class. English is often learned because of the doors it opens in the areas of science, technology, trade, and diplomacy.

\subsection{When and Why Colloquial Hybrid Terms and Expressions Are Used}

This section elicits data related to the second question of the study, when and why students use colloquial hybrid terms and expressions in Arabic discourse. The most frequent reasons for the use of hybrid terms and expressions amongst students are the following:

\subsubsection{The Presence of English Terms and Expressions Which Have No Equivalents in Arabic:}

Forty-eight students $(32.0 \%)$ said that they use hybrid terms and expressions because of the presence of English terms and expressions which have no or unknown Arabic equivalents to them. So they tend to use the English term and tense it using the Arabic tensing rules, making it sound as if it is of Arabic origin. The most frequently provided example was, /lābāt/ = لابـات - meaning Labs, another example is $\mid$ ttabāter $/=$ ش - meaning Chapters. As can be seen from the previous examples, different forms of pluralisation are used. In the Arabic language there are three main types of pluralisation:

- Regular Plural Form:

1). جمـع الـــكر السـالم (Masculine Plural Form).

2). جمـع الــؤنتث الســـالم (Feminine Plural Form).

- Irregular Plural Form:

3). جمـع التكسيـر (Broken Plural Form).

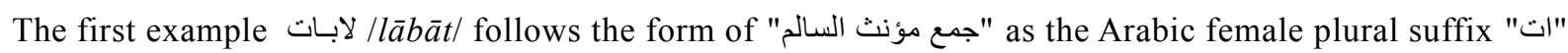
$/ \bar{a} t /$ is added to the end of the English word. "Lab $+\underline{a} t=l \bar{a} b \underline{\bar{a} t}$ ".

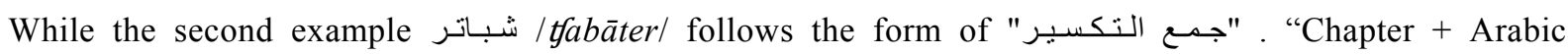
pluralisation form = chabāter".

\subsubsection{It is Easier to Express Scientific and Technological Concepts:}

Forty-four students $(29.33 \%)$ said that they use hybrid terms and expressions as they find it easier to express technological and scientific concepts when discussing topics related to certain subjects. English is considered the language of science, technology, internet, and education. In Jordan, universities teach their courses of science and technology in English. Teaching in English has contributed to the students' bilingual ability. Examples given for such reason are, /kumbouträt/ = كمبيوترات - meaning Computers. |flāaât/

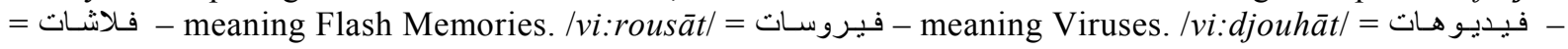
meaning Videos. /srinjāt $/=$ سـرنجـات - meaning Medical Syringes. $/$ sji:dji:hāt/ = سيديهات - meaning CDs.

\subsubsection{The Familiarity and Frequency of English Formulaic Expressions:}

Thirty-six students $(24.0 \%)$ said that they use hybrid terms or expressions because of the familiarity and frequency of English formulaic expressions. Students are exposed to the English language almost daily, due to this exposure to the English phonetics, especially the sound of word endings (suffixes), has become familiar and frequently heard. So students tend to add these endings to Arabic words to make them sound modernised. Five Female students stated that by adding English word endings (suffixes) to Arabic words makes them sound more musical and attracts the listeners attention.

Examples, /zifteIfon/ = زفتيشن - meaning Not Good. $|z o u P l I S|=$

\subsubsection{Spontaneous, Unconscious, and a Habit for Them:}

Sixty-four students $(41.33 \%)$ said that they use hybrid terms and expressions because they have become a spontaneous unconscious habit for them. They explained that it has become an habitual form of speech for them, especially when speaking with their friends and colleagues, they tend to unconsciously and spontaneously use these kinds of terms and expressions. "It is unconsciously natural to use these expressions as they have become a part of our everyday lexical array". 
Examples, /noutāt/ = نوتنات - meaning Notes. /lektfrāt/ = كشرات - meaning Lectures.

3.2.5 To Create a Warm, Friendly Atmosphere Amongst Interlocutors:

Forty-five students $(30.0 \%)$ stated that they use hybrid terms and expressions because it creates a warm and friendly atmosphere amongst friends and colleagues. People are more playful with their friends. This suggests that people tend to be more playful with language use with their friends. There is no motivation for this language playfulness other than fun and there is no rhyme or reason for this playfulness. One student's responded with "These terms help us to express and show intimacy between friends". The Playful/Friendship genre serves to illustrate the fluidity of the members of the group, as they weave the two languages together at both structural and lexical levels.

Examples, /frinzāt/ = فرنزات - meaning Friends. /gezdareIfon/ =زدريشن - meaning Go For A Walk. Inatanskfl = نتنسكف - meaning Drinking Nescafe.

\subsubsection{To Attract the Attention of Others:}

Twenty-six students (17.0\%) stated that they use hybrid terms and expressions to attract the attention of their friends and sometimes other listeners. They stated that "when we want to emphases on something or attract others attention, we tend to use these terms as they give a different tone and pitch then just simple Arabic or English words".

Examples, /zouPlis/ = زوئلس - meaning Has No Manners. /lovkom/ = لفكم - meaning Love You All. /hajāt/ = هـايLات - meaning Many Hi (Hellos).

\subsubsection{Because Their Friends Do So:}

Nine students $(6.0 \%)$ said that they use hybrid terms and expressions just because their friends do. Students explained that the only reason why they use these terms and expressions is because everyone else around them uses them, and they just want to fit in. "I only use these expressions when I speak with my friends or when at university, basically just because they use them".

\subsubsection{Liking English:}

Five students (3.33\%) stated that they use hybrid terms and expressions because they like English. When asked why they use hybrid terms and expressions, they simple answered: "because I like/love English, that's it!".

\subsection{The Extent of the Use of Colloquial Hybrid Expressions amongst Students}

In addressing the final question of the study, this section elicits data related to student's proficiency in English verses Arabic, language mixing, and the hybrid terms and expressions that they frequently use in Arabic discourse.

\subsubsection{Students' Proficiency in English and Attitudes towards Language Mixing}

The informants were, as mentioned above, 79 males and 71 females, only 50 students $(33.33 \%)$ provided oral data -25 males and 25 females, their age varying between 18 to 23 years old. Their level of education also varied, mostly first, second and third year students. All of them were familiar with the English language but their level of mastery and preferences varies. A total of 14 questions were asked to each student.

The first question addressed students' proficiency in English, each student was asked to rate their own proficiency in English from a scale of "Excellent" to "Weak".

1). How do you rate your proficiency in the English language?

The results of the students' proficiency, $16.0 \%$ judged themselves to be "excellent" and "very good", whereas $68.0 \%$ judged themselves to be "good", and $16.0 \%$ judged themselves to be "average" and "weak". It also shows that females (10.0\%) judge themselves to be more proficient in English then males did (6.0\%).

However, language proficiency alone does not show the extent of English and its affect on the Arabic speech amongst students. To evaluate students' extent and attitudes towards the use of English, the following questions were also asked:

\section{2). Which language do you prefer, a part from your mother tongue?}

The results indicate that students' language preference were almost equally divided between the two languages, Arabic and English. 48.0\% prefer Arabic and 46.0\% prefer English, while only $8.0 \%$ prefer both. Females showed more interest and preference to English. Arabic is more appreciated and favoured by males 
and their arguments were more prominent than the females. The males stated that Arabic is evidently a language of wider communication in Jordan and in spite their real interest of English they were more talkative about Arabic, contrary to females, who described the English language as a prestigious one. The gap between males and females preferences was prominent: males prefer Arabic and females English.

To measure students' language perception in terms of difficulty, the researcher asked the following question:

\section{3). Which is the most difficult language?}

The results indicate that English seems to be the most difficult language for both males and females. Males showed more difficulties in English $30.0 \%$, and stated that even if Arabic remains a difficult language in terms of form and content; English still is for them a difficult language to learn and to produce. Out of 25 males, 15 said that English is, for them a difficult language, and the researcher noticed that these students come from rural areas, where they said that they had not been well taught in the English matter from the beginning, and that the English language is very seldom used in the area where they live. For Females, English is obviously easier than Arabic in all contexts. Indeed, English grammar, they explain is more simple than Arabic. Females prefer to use the English language when conversing with others than do males. Even those females, who find English to be a difficult language, stated that they are not able to use English easily, but they are interested in mastering the English language and consequently motivated to learn it appropriately.

To go deeper, and know how students perceive the English language in comparison with their mother tongue, the researcher asked them to give her their impression in terms of the beauty of the two languages.

\section{4). Which is the most beautiful language?}

Not surprisingly, Arabic is the beautiful language of the majority of the students $48.0 \%$. However, it is noticeable that females are more in favour of the English language than males. Females said that the Arabic language is a beautiful language, but English is also beautiful in terms of its simplicity and prestige. This question aimed mainly at showing if the students' attitude towards the English language maybe indirectly influenced when speaking about the beauty of the two languages and if maybe incite them to reveal what they really think about English, because it is known that attitudes towards the mother tongue is mostly positive. Student's, mainly males $28.0 \%$, are very proud of their native language Arabic, and they do not neglect the importance of English which they said is part of their speech and life.

After asking students about their feelings and perception of both Arabic and English, we moved to their daily speech considering the two languages. Questions were to be answered according to their daily speech at university, as to show the influence of English lectures, and to evaluate the degree of language mixing among students.

\section{5). Do you mix Arabic and English when speaking?}

The results obtained were revealing, out of 50 students (male and Female); 29 (58.0\%) stated that they use both English and Arabic, and $14(28.0 \%)$ stated that they sometimes use both languages when speaking, which indicates certainly the vast amount of English used. As expected, females (34.0\%) showed to use both languages more than males $(24.0 \%)$. Though responding with "sometimes", males $(22.0 \%)$ showed a higher percentage them females $(6.0 \%)$.

To know how much English is used in the daily life of students, students were asked which language they use most when speaking with friends. Certainly Jordanian Arabic is the language used in the daily speech of Jordanians, but let us sees the degree of English use. Also, they were asked to explain their need of English use in their daily communication.

\section{6). Do you feel the use of English is necessary when speaking?}

The results indicate that students are divided, 44.0\% "Yes" and 40.0\% "No", in belief whether the use of English during Arabic discourse is necessary or not. This shows that students language mix consciously and unconsciously, making it hard to know the real reasons behind some language mixing situations.

To know students attitude towards the use of English during Arabic discourse, the students were asked about how they felt about the presents of English during speaking Arabic with friends.

\section{7). How do you judge someone who uses a lot of English when speaking Arabic?}

The results showed that $72.0 \%$ of males and females answered with "Indifferent". Indicating that nowadays 
no one really criticises someone for speaking English. Thus, people are somehow indifferent about the use of English in daily speech. There are some people who find it positive to use English and only a few find it negative, the informants said that we can distinguish between those who are educated and those who are uneducated from their level in English. If a person speaks English well, even if this person is not educated, they know that he or she is a person of a certain level.

The last question was established to know if the students are influenced by English as a future language in Jordan. As noticed before, a great number of males did not feel themselves at ease with the English language. These deficiencies do not stop them from expecting English as becoming a future Second language in Jordan. The English language is an appreciated language by many around the world.

8). In the future, what language do you think will become dominant in Jordan?

English is still a language that is mainly appreciate by females (18.0\%). For males, Arabic is the language of their religion, but they stated that it will be interesting and beneficial to invest more in English in the future because they consider it to be an important language worldwide, the language of mass communication.

\subsection{The Colloquial Hybrid Terms and Expressions Frequently Used by Students in Arabic Discourse}

Item 25 of the questionnaire, elicited data on the use of hybrid terms and expressions that students use in colloquial Arabic discourse. Listed below are some hybrid terms and expressions, alongside with their frequency of occurrences as indicated by the students. Terms and expressions with frequencies ranging between 104 and 9 are listed below. Terms and expressions with frequencies of less than 9 are not listed.

Table 2. Terms and expressions with frequencies

\begin{tabular}{|c|c|c|}
\hline Term/Expression & Meaning & Frequency \\
\hline mesijli & send me a message & 104 \\
\hline$l \bar{a} b \bar{a} t$ & labs & 102 \\
\hline tabātr & chapters & 102 \\
\hline kuizāt & quizzes & 100 \\
\hline kensilha/kensilit & cancel it/cancelled & 99 \\
\hline sajav/sajavha/sajavit & save it/saved & 97 \\
\hline gougilha & Google it & 92 \\
\hline fasboki & my Facebook & 90 \\
\hline JejakIt/Jajak/te/jek & checked it/checked & 89 \\
\hline groubāt & groups & 86 \\
\hline likāt & likes & 86 \\
\hline comintāt & comments & 84 \\
\hline zouPlis & has no manners & 84 \\
\hline frmateh & format & 82 \\
\hline zifteIfon & not good & 81 \\
\hline vi:rousāt & viruses & 80 \\
\hline tanasit/tfanas-ha & chanced it & 78 \\
\hline fallal & filled it & 77 \\
\hline fana/It & finished & 75 \\
\hline kumboutrāt & computers & 74 \\
\hline flajăt & flash memories & 70 \\
\hline mobili/ mobilāt & my mobile/mobiles & 70 \\
\hline telfinli & phone me & 68 \\
\hline lovik/lovkom & love you (all) & 67 \\
\hline
\end{tabular}




\begin{tabular}{|c|c|c|}
\hline misik/miskom & miss you (all) & 67 \\
\hline fouzāt/fouzi & shoes/my shoes & 64 \\
\hline gezdareIfon & go for a walk & 63 \\
\hline $\operatorname{tag} \bar{a} t$ & tags & 60 \\
\hline lābtobi/lābtobāt & my laptop/laptops & 57 \\
\hline hajāt & many hi (hellos) & 54 \\
\hline noutāt & notes & 52 \\
\hline mesijāt & messages & 3 \\
\hline kofyefobāt & coffee shops & 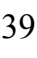 \\
\hline lokrāt & lockers & \\
\hline molāt & malls & 20 \\
\hline fiftāt & shifts & 18 \\
\hline blastrāt & plasters & 16 \\
\hline srinjāt & medical syringes & \\
\hline songayeh & one song & \\
\hline
\end{tabular}

What characterises some of these terms and expressions above is their diffusion among the educated people in the Jordanian society, to the extent that they have almost entirely substituted the Arabic equivalents.

\section{Summary and Conclusion}

This present study, which arose primary from sociolinguistic interests, is an introductory step towards the identification of attitudes and extent of use of colloquial hybrid terms and expressions used by students of some Jordanian universities during Arabic discourse amongst friends and colleagues. As perceived by a sample of 150 university students at Yarmouk University, representing different faculties and departments. Participants were of various age groups, gender, major, and educational level. It was also aimed at identifying when and why students use colloquial hybrid terms and expressions and the most frequently used terms and expressions during Arabic discourse.

Both qualitative and quantitative research approaches were combined in an effort to obtain accurate outcomes and sufficient information from the respondents. In order to measure students' attitudes towards colloquial hybrid terms and expressions used in spoken communication among students in some Jordanian universities, a questionnaire of 24 items was administered to the participants. The researcher also conducted group interviews, where participants were asked 14 oral questions, in order to measure the extent of English used in the daily speech of students in the university domain.

The provided responses by participants constituted the corpus of the study. The gathered data were checked if related to any set of categories with a door open for registering any emerging category. All identified colloquial hybrid terms and expressions used were tabulated, described, and compared in relation to the intended social variables.

The research revealed the following conclusions. Generally, attitudes towards the presence of the English language in Arabic discourse was positive while only a small number of students presenting negative attitudes. Additionally, attitudes towards the future status of the English language in Jordan where mixed; with a majority stating that the status of the English language might change from being a foreign language to becoming the second language of the Jordanian people.

With regard to students' preference of the language used as a medium of instruction, students showed a strong preference toward a specific medium of instruction that is Arabic-English intertwined, i.e., a mixture of both languages; Arabic and English.

Moreover, with regards to students' extent and attitudes towards the use of hybrid terms and expressions during Arabic discourse, in relation with the variables in question; gender, age, major, and educational level, the findings indicate the following:

1). A strong preference was shown by both genders; females showing more preference than males, for using these terms and expressions. 
2). In relation with age, the findings indicate that hybrid terms and expressions are used by most - if not all age groups; yet mainly by those ranging between 18 and 20 years of age, as these terms and expression serve as a "cool style" of communication amongst the youths of today in Jordan.

3). In relation with students' major and level of education, their responses, to both the questionnaire and oral questions, showed that there is no direct relation between either the major in which students are enrolled in nor their level of education (university year) and the use of colloquial hybrid terms and expressions. This is in line with Bani-Ismail (2012), stating that students' major and level of education do not play any role in the use of Arabizi.

Furthermore, the use of colloquial hybrid terms and expressions is widely used in the university domain, but not every speaker is aware that s/he uses hybrid terms and expressions in his/her daily life during Arabic discourse. Moreover, colloquial hybrid terms and expressions were found to be used in informal situations, like chatting and natural talk amongst not just friends and colleagues, but also between students and their instructors; i.e., doctors, professors, and university staff members.

In conclusion, colloquial hybrid terms and expressions reflect ways of thinking and the kinds of relationships between people, i.e., they reflect culture. In other words, colloquial hybrid terms and expressions are rich in linguistic, cultural, and psychological information that reveals many important aspects of life of the people living in Jordan.

\section{Reference}

Arends, J., Muysken, P., \& Smith, N. (1994). Pidgins and Creoles: An introduction, Creole Language Library. John Benjamins Publishing. http://dx.doi.org/10.1075/cll.15

Bani-Ismail, I. T. (2012). Arabizi as Used by Undergraduate Students in Some Jordanian Universities: A Sociolinguistic Study. Unpublished MA Thesis. Irbid: Yarmouk University, Jordan.

Bassiouney, R. (2009). Arabic Sociolinguistics. Edinburgh University Press. http://dx.doi.org/10.3366/edinburgh/9780748623730.001.0001

Crystal, D. (2008). Dictionary of Linguistics and Phonetics (6th edition). Malden, MA, Oxford: Blackwell Pub. http://dx.doi.org/10.1002/9781444302776

Giles, H. (1973). Accent Mobility: A Model and Some Data. Anthropological Linguistics, 15(2), 87-105.

Giles, H., Coupland, J., \& Coupland, N. (1991). Accommodation Theory: Communication, Context, and Consequence. In G. Howard, C. Justine, \& N. Coupland (Eds.), Contexts of Accommodation. New York, NY: Cambridge University Press. http://dx.doi.org/10.1017/CBO9780511663673

Hanani, Fatiha. (2009). Impact of English on Young Arabs' Use of Arabic in the UAE. MA Thesis. The American University of Sharjah. UAE.

Hernández, D. (2003). A Hybrid Tongue or Slanguage? Los Angeles Times. Los Angeles Times, 27 Dec: A30.Web. 19 Nov. 2014.

Hussein, R. F. (1999), Code-Alteration among Arab College Students. World Englishes, 18, 281-289. http://dx.doi.org/10.1111/1467-971X.00141

O'moush, Lama' - Muhammad. (2003). A Sociolinguistic, Lexical and Syntactic Study of Some Colloquial Idiomatic Expressions: A Case Study. Unpublished MA Thesis. Irbid: Yarmouk University, Jordan.

Yaghan, M. A. (2008). Arabizi: A Contemporary Style of Arabic Slang. Design Issues, 24(2), 39-52. http://dx.doi.org/10.1162/desi.2008.24.2.39

\section{Copyrights}

Copyright for this article is retained by the author(s), with first publication rights granted to the journal.

This is an open-access article distributed under the terms and conditions of the Creative Commons Attribution license (http://creativecommons.org/licenses/by/3.0/). 